\title{
ATTITUDES OF SCHOOL PRINCIPALS AND TEACHERS TOWARDS COMPUTERS: DOES IT MATTER WHAT THEY THINK?
}

\author{
Willem J. Pelgrum
}

Faculty of Educational Science and Technology, University of Twente, The Netherlands

\section{Introduction}

The introduction of computers in education can be seen as an innovation unprecedented in scale, cost and presumed claimed effect. Pelgrum \& Plomp (1991) show that in most countries there is a consistent increase of the amount of computer equipment in schools at all levels (primary, lower secondary and upper secondary) and that increasing numbers of teachers use computers in their lessons. Still, the percentage of teachers that apply computers to a substantial extent is relatively low.

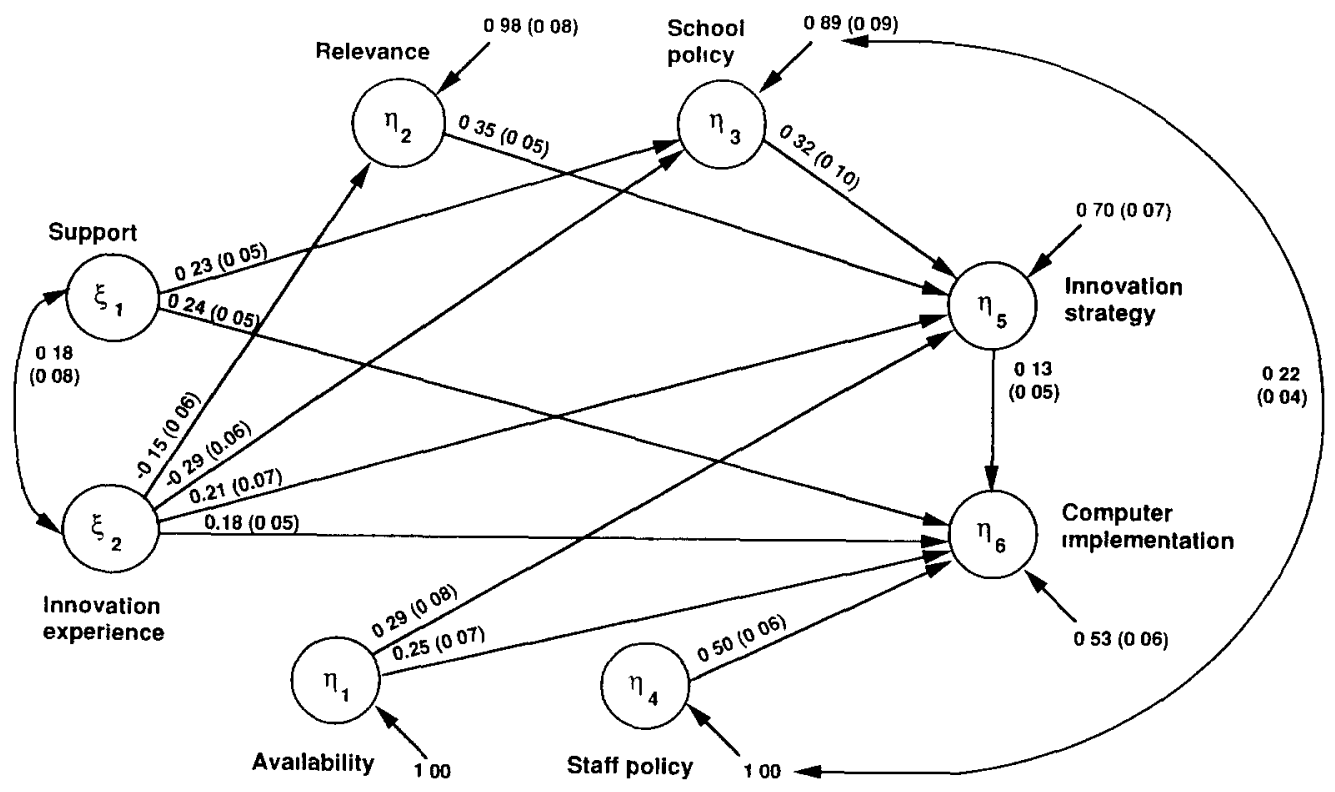

Figure 1: Standardized Effects on Innovation Strategy and Computer Implementation, U.S. School Data (standard errors in parenthes1s), from Pelgrum \& Plomp, 1991 
Although in the USA many schools already started to introduce computers in the early 1980s, Becker (1992) estimates that in 1989 "the proportion of exemplary teachers [that is, teachers who integrate computers to a substantial extent, WJP] among all teachers of the studied subjects [mathematics, science and mother tongue, WJP] and grade levels is only 3\%". Many potential explanations can be offered for this finding, but it would be unrealistic to search for simple explanations, or as Collis (1988) notes "What we know most clearly about the impact of computers in education is that this impact depends on many other things. We know we are dealing with a network of interconnected variables, where an alteration in any of them can affect the entire system". More insight into this interrelatedness of different factors can be acquired by conducting empirical research. Pelgrum \& Plomp (1991) offered some first evidence regarding this issue, based on an international comparative survey of computer use in 22 countries. Figure 1 illustrates that, indeed, many factors play (directly or indirectly) a role in determining the amount of computer implementation in schools in the USA. Figure 1 illustrates, amongst other things, that attitudes of school principals (the factor "Relevance" in the model) play a role in determining to what extent computers are used. It confirms what has been claimed in the literature on educational change, namely that attitudes of participants involved in an educational innovation are important factors in determining to what degree and with what speed change will be effected (Fullan, Miles \& Anderson, 1988). A nice citation to illustrate this point is given by Cox, Rhodes, \& Hall (1988):

I know there are schools where the headteacher is very computer orientated, so there's leadership from the top, but not here. In hindsight it's obvious that if I were as computer aware we would have made better progress (headteacher).

In this paper we will try to shed some further light on the question how principals and teachers in different countries think about the usefulness of computers, how their opinions covary with indicators of computer use, and how differences in opinions between respondents might be explained. The data used were collected in the IEA Comped study (for details about the design see Pelgrum \& Plomp, this issue) in which a number of attitude scales were administered to school principals in schools using computers as well as in non-computer-using schools. Furthermore, these scales were also administered to teachers involved in teaching computer education courses and computer using as well as non-using teachers in mathematics, science and mother tongue. In this paper we will first give a description of the scales and the results for a number of countries participating in the IEA Computers in Education survey. Next, we will present some empirical evidence as to how attitudes of principals and teachers covary with indicators of computer integration.

\section{Attitude Scales}

The attitudes of principals, computer education teachers and teachers in existing subjects (mathematics, science and mother tongue) were measured with a list of respectively 15,22 and 33 attitude items. The list of items for teachers in existing subjects is the most comprehensive one, and from it subsets that were considered appropriate for the other respondents were selected. 
Table 1: Content of Attitude Items for Each Category of Respondents

\section{Scale/Respondents* Content Attitude Item}

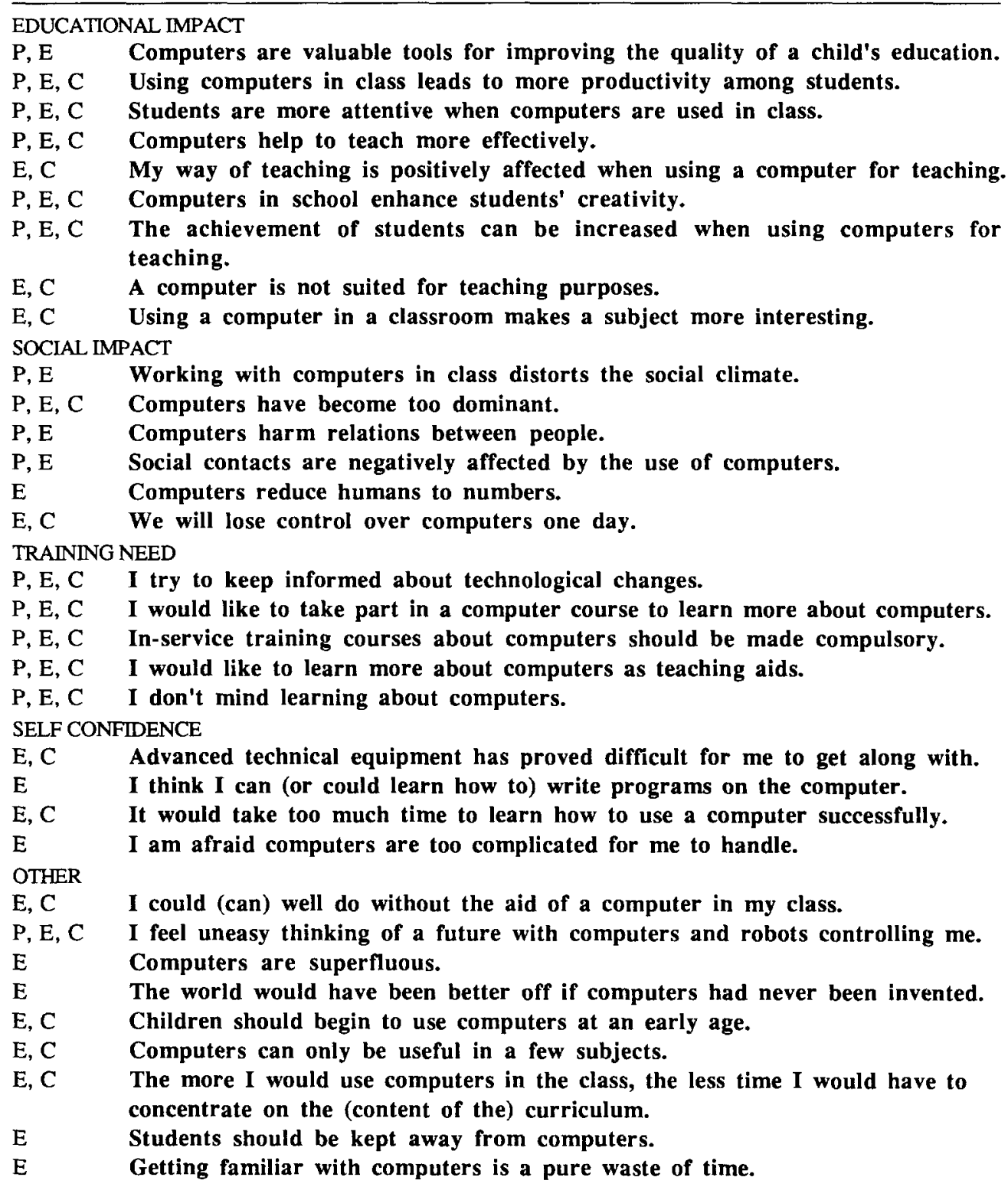

*: $\mathrm{P}=$ Principals $; \mathrm{E}=$ Teachers existing subjects $; \mathrm{C}=$ Computer education teachers 
In the construction of this list three dimensions were distinguished, namely (1) Perceived Educational Impact, (2) Perceived Social Impact and (3) Training Needs. For teachers there is an additional dimension, namely (4) Self Confidence, that was excluded from the list of attitude items for principals.

The ultimate attitude scales administered in the main run were constructed after pilot testing in England, the Federal Republic of Germany, Greece and the Netherlands. The full list of attitude items is shown in Table 1.

As a first check on the dimensions represented in the data, the attitude data of the three groups of respondents across countries were analyzed with PCA (principal component analysis) after recoding the negatively formulated items to reflect positive statements. Moreover, reliability analyses were conducted within each country for each category of respondents.

The PCA-analyses confirmed the existence of the predefined dimensions, whereas the reliability analyses showed that the reliability coefficients for each scale are quite similar across most countries: the scales Educational Impact and Self Confidence have reliabilities between .80 and 90 , Social Impact between .70 and .80 , and Training Need is generally the lowest with a reliability between .50 and .70 , which is still quite high for a five item scale.

Tables 2 and 3 show the results of the attitude measures taken from principals and teachers, whereby data from systems with less than 50 valid cases in a particular category were dropped. The results in Table 2 show as a general pattern across educational systems a high degree of agreement with the items in each scale. Some remarkable exceptions are constituted by the principals in elementary schools in France and the Netherlands (and to a lesser extent in Belgium-French) who are less positive about the educational impact of computers than their colleagues in other countries. Further inspection of the data for the Netherlands showed that this results from the fact that many principals are uncertain about the educational impact of using computers rather than having negative opinions.

In lower secondary schools principals from central European countries tend to be less positive about the educational impact of computers than their colleagues elsewhere, whereas for upper secondary schools this is the case in the Federal Republic of Germany, the Netherlands and Switzerland. Furthermore one may observe that especially on the scale Social Impact the Japanese principals in upper secondary schools are less positive than their colleagues in other countries.

Table 2 does not show a consistent pattern of differences for all scales and countries between principals of computer-using schools and their colleagues in schools that do not use computers, although there is a trend to the effect that principals from computer-using schools have more positive attitudes than principals from schools not using computers.

Most surprising in Table 2 are the huge differences (quite consistent over populations) between certain systems on the scale Educational Impact: for instance in elementary schools the USA (83) versus the Netherlands (50); in lower secondary schools, the USA, British Columbia, New Zealand (83-100) versus Switzerland (33) and the Netherlands (50).

Table 3 shows that teachers who are using computers are generally quite positive about the educational impact of computer use. This is the case in most educational systems, with the exception of Switzerland where the median scores are quite low. This finding is consistent with the one reported above for principals. 







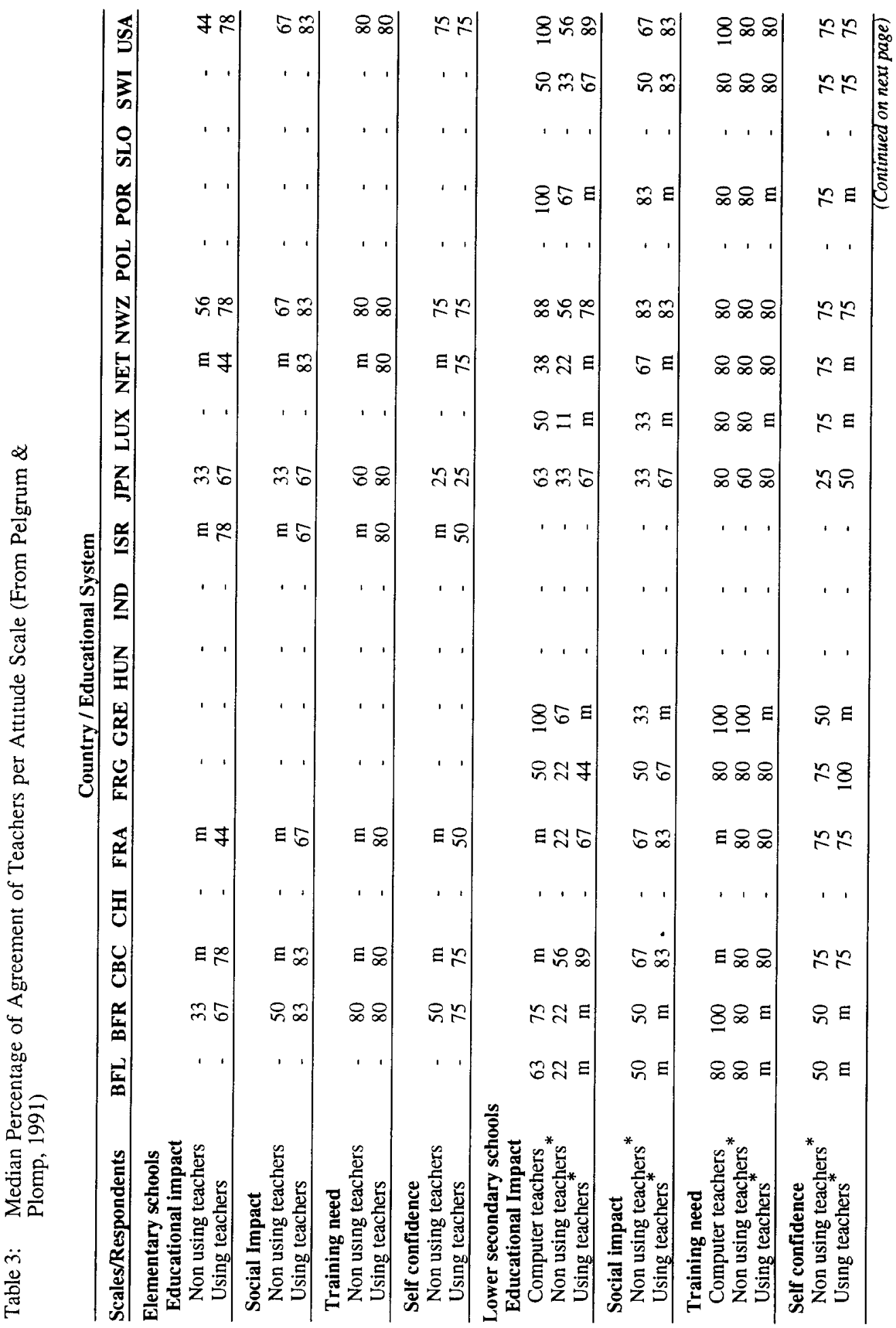




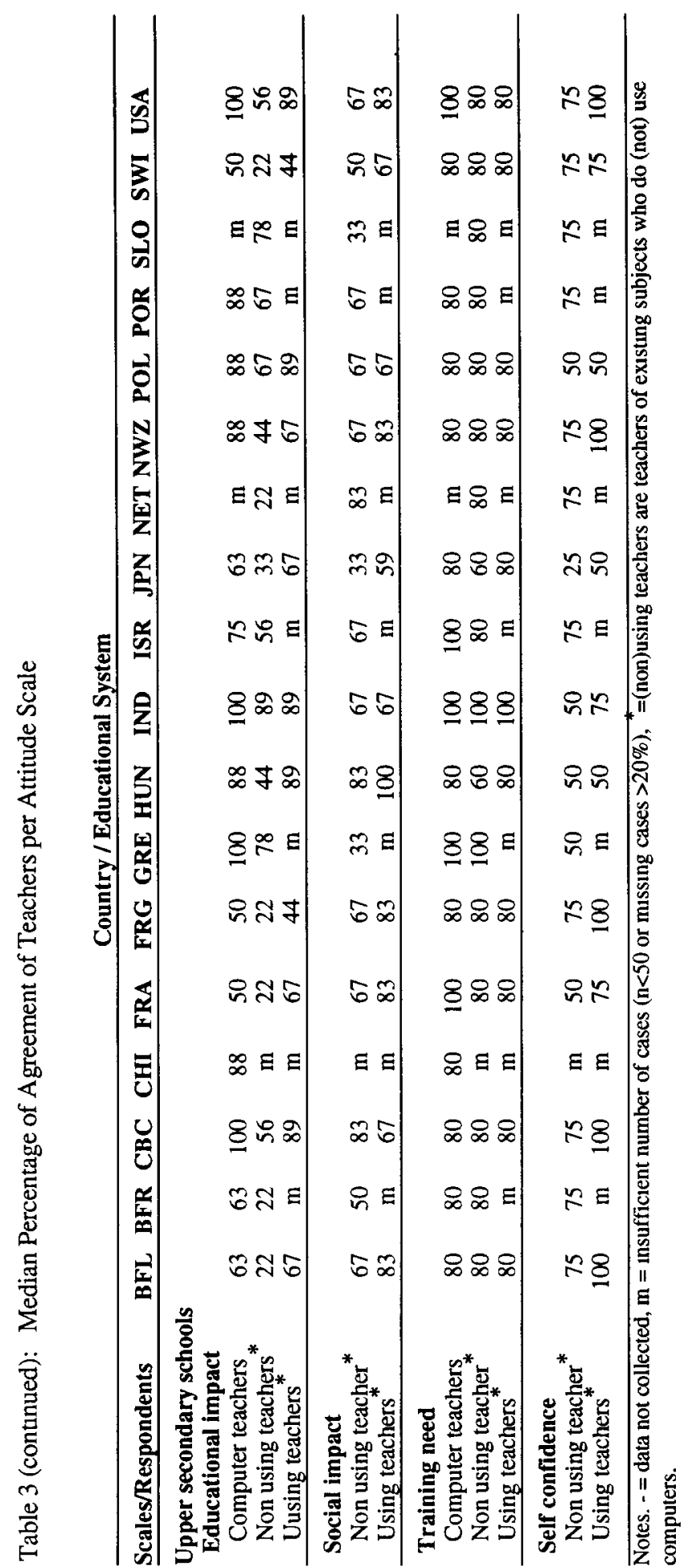


In contrast with the findings reported for principals, the teachers that are not using computers score much lower than their computer-using colleagues.

In most educational systems the teachers who use computers are quite positive about the social impact of computers in the sense that they generally disagree with negative statements related to this issue. Teachers not using computers are less positive with respect to this issue except for lower secondary schools in New Zealand where the scores are almost the same. The agreement with the items in the subscale Training is very high for using as well as non-using teachers, and also for computer education teachers showing on the one hand that in most systems even the non-computer-using teachers are very interested in learning about computers, but, on the other hand, that computer-using teachers, too, apparently consider themselves as not yet sufficiently trained.

In contrast with this finding it seems from Table 3 that teachers of existing subjects who use computers feel reasonably confident about their capacity of working with computers, while in quite a number of systems their non-using colleagues tend to feel less confident.

\section{Do Attitudes Make a Difference?}

In Tables 2 and 3 it was shown that attitudes of respondents are quite different, within as well as between countries. In this section we will zoom in on the scale Educational Impact and restrict ourselves to lower secondary schools in order to analyze in greater depth how the results may be interpreted.

One may expect that respondents who are very positive about the educational impact of computers will behave differently in terms of how they use computers than respondents which have negative attitudes. Although Figure 1 already illustrated that attitudes of principals make a difference in terms of their relation with what happens in the school regarding computer use, it is interesting to explore these attitudes in some more detail.

Therefore, in this section, we will highlight the following questions:

1. Are attitudes of principals and teachers related to each other?

2. Do attitudes of school principals covary with what happens in the school?

3. Do teachers with positive attitudes integrate computers more than their less positive colleagues?

Relation between Attitudes of Principals and Teachers

As the literature on educational change suggests, one may expect that principals with very positive attitudes may induce positive attitudes in their teaching staff. This hypothesis seems to be confirmed by the graph in Figure 2, which shows that for the total sample an increase in principal attitudes tends to be associated with an increase in teacher attitudes.

One problem in interpreting Figure 2 is whether the graph simply reflects covariation caused by some other variable or whether a causal link may be hypothesized that there is. One way to study the plausibility of a causal link between these two variables is by trying to find evidence for the existence of a plausible mechanism by which attitudes of principals may influence those of teachers. 


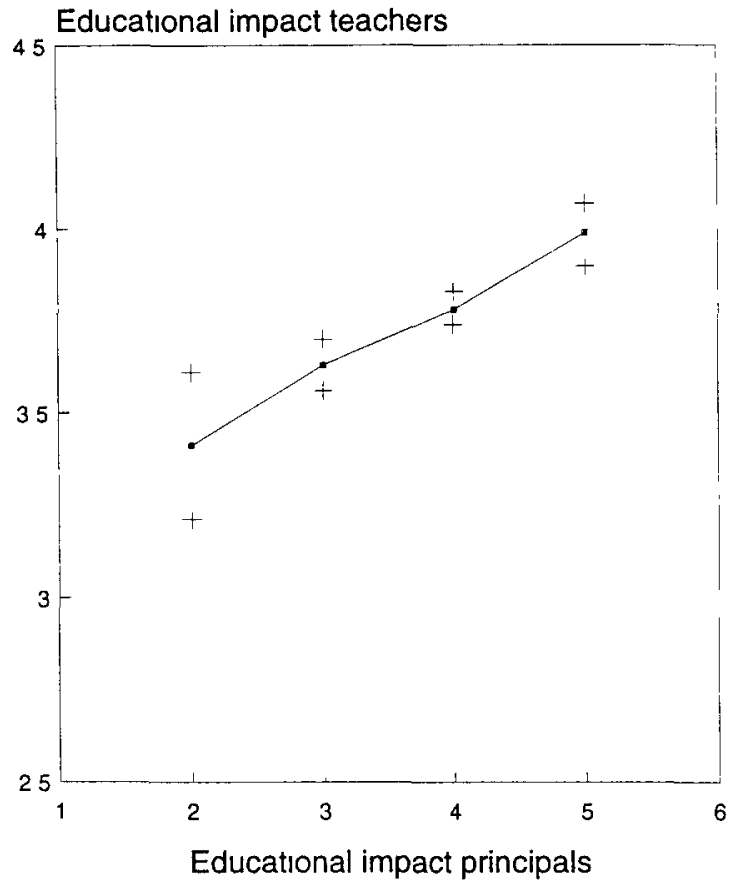

Figure 2: Educational Impact Attitudes of Teachers Broken Down by Educational Impact Scores of School Principals (+: $95 \%$ confidence interval)

If for instance we can demonstrate that principals with positive attitudes give more support to their teachers than principals with negative attitudes the tenability of assuming a causal link increases. Figure 3 shows the principal attitudes broken down by frequency of stimulation of computer use by school authorities. Figure 3 shows that school principals with positive attitudes towards the educational impact of computers report a higher frequency of stimulation of computer use by school authorities than principals with a less positive attitude. This finding may be interpreted as giving some support to the hypothesis that there is a causal relation between principal attitudes and teacher attitudes.

Attitudes of School Principals and Integration

As pointed out elsewhere (Anderson \& Collis, this issue), there are several perspectives or models regarding the goals of computer use. A main distinction is between learning about computers (sometimes called the technical model) and learning with computers (sometimes referred to as the integration model or the functionality perspective). The evolution of these models can be seen as a typical product of the 1980 s. In the early 1980s computer hardware and software characteristics were such that "..one often had to write a program in Basic, Fortran or Pascal to accomplish a computer related task" (Anderson \& Collis, this issue). Later, the concern for integration grew and in the early 1990 s one of the main questions is how integration might be promoted. 


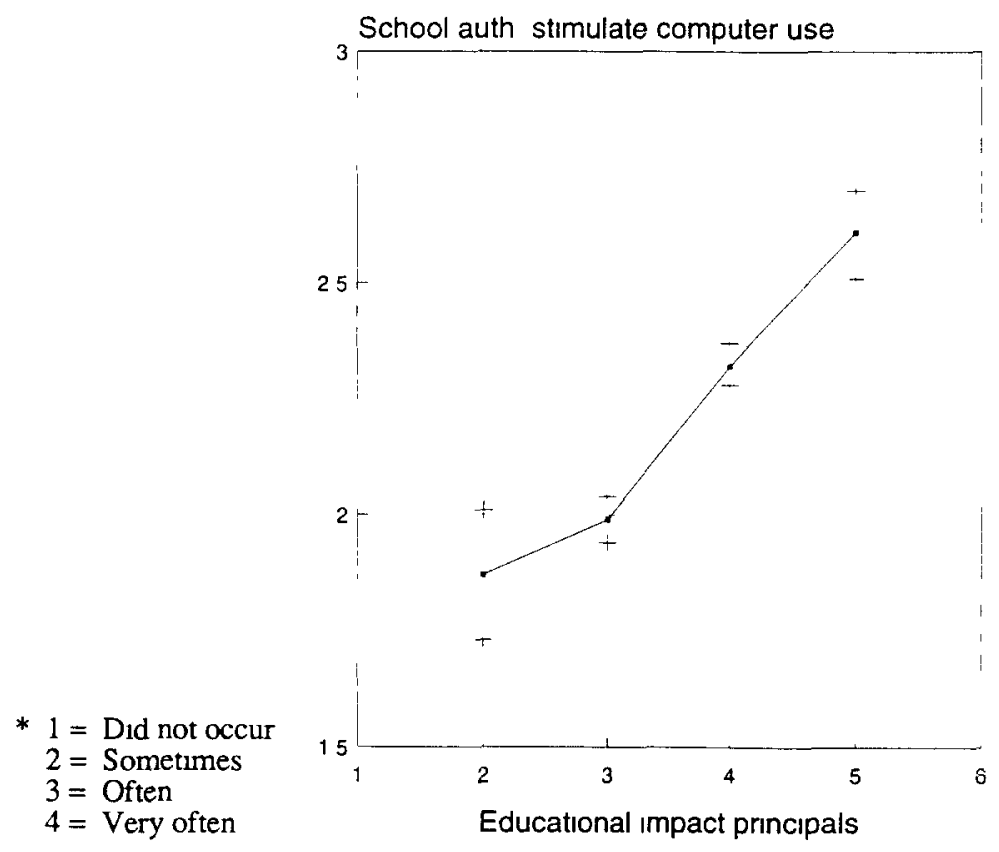

Figure 3: Educational Impact Attitudes of School Pnncipals and Frequency of Stimulation of Computer Use by School Authorines (+: $95 \%$ confidence interval) *

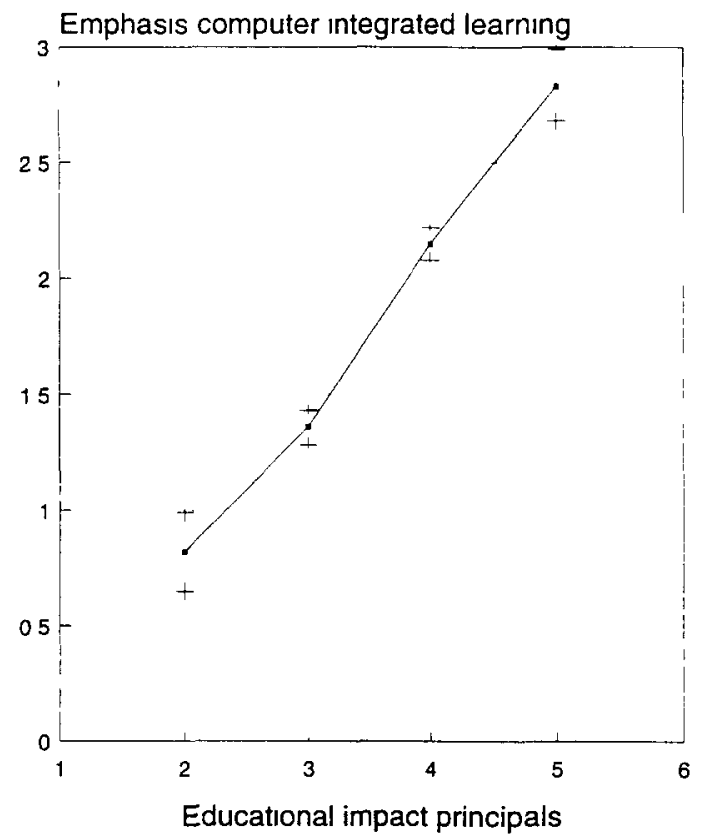

Figure 4: Educational Impact Attitudes of School Principals and Emphasis on Computer Integrated Learning ( $+: 95 \%$ confidence interval) 
Therefore, in the context of this article, the question is relevant as to what extent attitudes of school principals affect the amount of emphasis on computer integrated teaching and learning in the school. In order to answer this question we will use an indicator for computer integration at school level as discussed by Pelgrum \& Schipper (1992).

Figure 4 shows that there is a clear association between the attitudes of school principals and the emphasis on computer integrated learning within the school. This finding lends some support to the hypothesis that schools whose principals have positive expectations regarding the educational impact of computers tend to emphasize computer integrated learning more than schools with principals who are less positive.

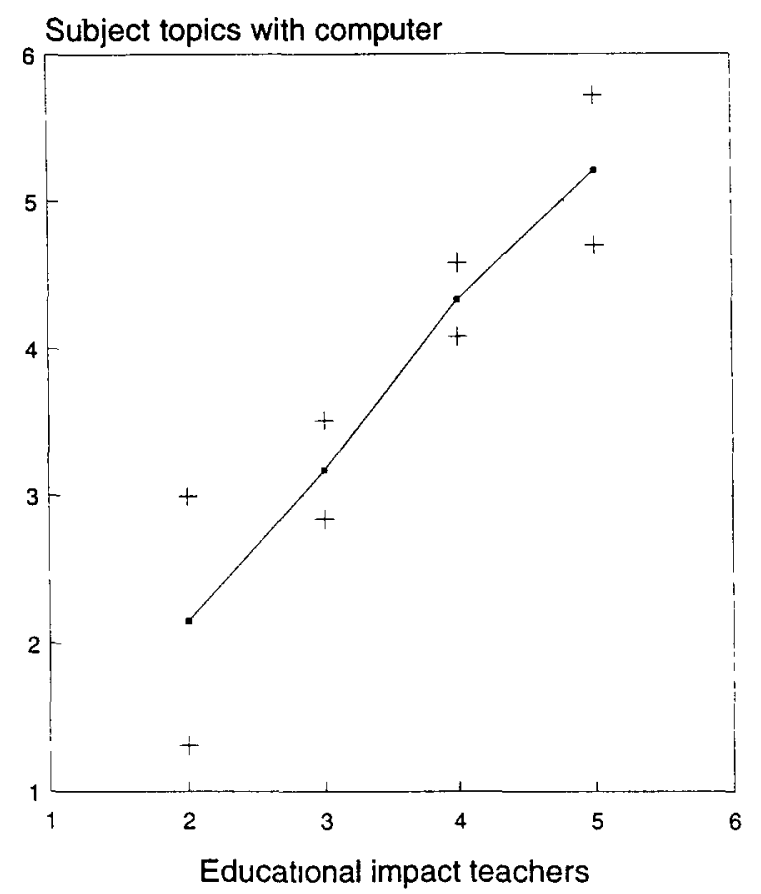

Figure 5: Educational Impact Attitudes of Teachers and Number of Subject Matter Topics for Which Computers are Used ( $+: 95 \%$ confidence interval)

Teacher Attitudes and Integration

Do teachers with positive attitudes behave differently in terms of how they use computers than colleagues who are less positive? This question can clearly be answered affirmatively by pointing to Figure 5 and 6 which show that teachers with positive attitudes on educational impact of computers tend to use computers more intensively for teaching subject matter topics, and those teachers especially tend to be inclined to use computers more frequently for enrichment and remediation. Maybe, as a result of this focuss on using computers as productivity tools, teachers with positive attitudes also indicate more frequently that they observed improvements in student achievement. 


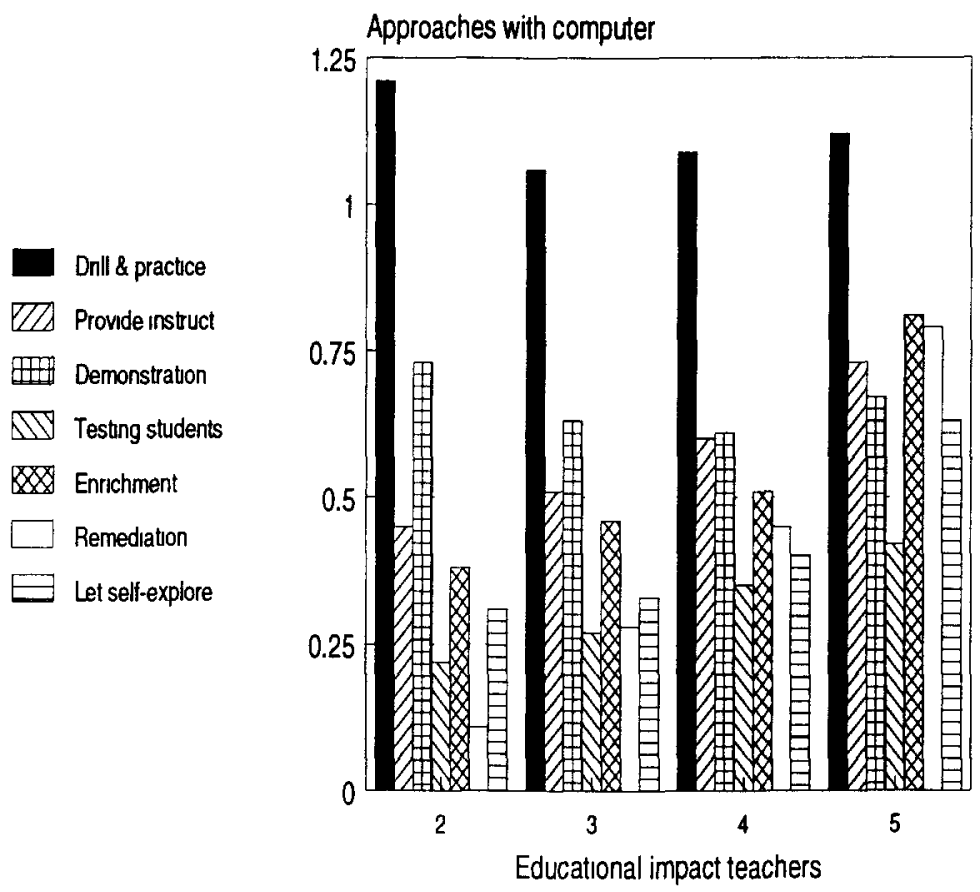

Figure 6: Educational Impact Attitudes of Teachers and Average Frequency of Using Computers for Certain Instructional Approaches $(0=$ not used: $1=$ some weeks: $2=$ most weeks: $3=$ every week)

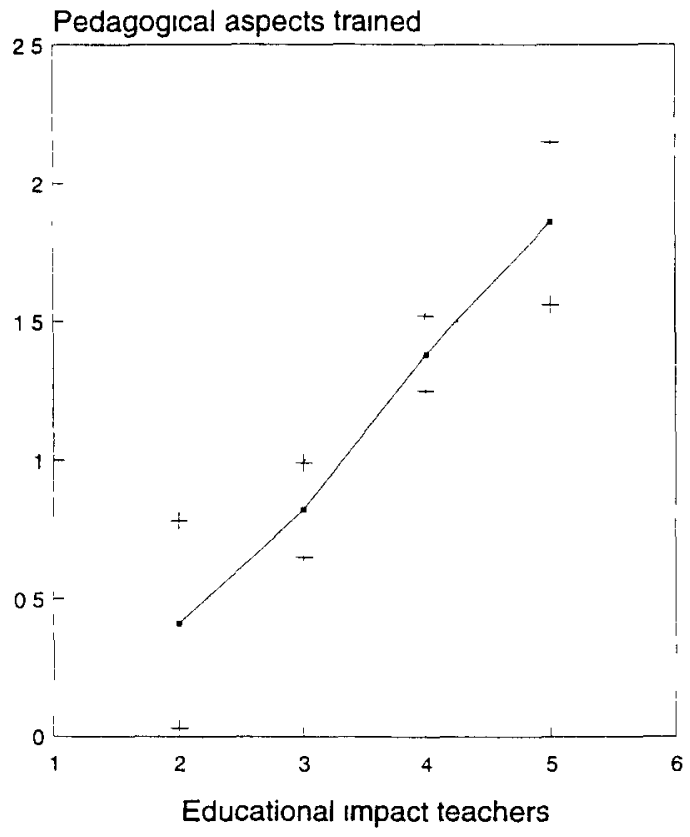

Figure 7: Educational Impact Attitudes of Teachers and Amount of Training on Pedagogical/Didactical Aspects of Using Computers ( $+: 95 \%$ confidence interval) 
A further analysis of the data showed that the likelihood of a teacher with a score at the low end of the attitude-scale to agree with the statement "I have perceived increases in student achievement as a result of using computers" is about .20 , while this is .70 for teachers at the high end of the scale.

\section{Atritudes of Teachers and Principals: Can They be Changed?}

The above sections suggest that evidence can be found in the data from the IEA Comped project that attitudes of school principals and teachers about the effectiveness of using computers for promoting student achievement is a potentially important factor in the way computers are used in a school. Such an inference immediately generates the question of what can be done to promote positive attitudes. Common sense suggests that provision of information could be an adequate strategy. Such information could, for instance, consist of 'journalistic' summaries of main findings regarding the effectiveness of computer integrated teaching and learning, containing 'convincing' examples of good educational computer use. There are some indications in the data which might support such a suggestion. We found, for instance, that the amount of information teachers received in training courses about pedagogical/instructional aspects of using computers is quite strongly associated with their attitudes about the educational impact of computers (see Figure 7).

If one poses the question whether measures aimed at changing attitudes should favor certain groups of respondents more than others, the data from our study only suggest that somewhat more attention might be given to females who seem, on the whole, to be somewhat less positive about the educational impact of using computers than their male colleagues. Characteristics like age and number of years of experience in using computers do not seem to play an important role.

\section{Summary}

In 1989, the IEA Computers in Education study collected data on computer use in elementary, lower- and upper secondary schools in 22 educational systems. The data collection included attitude measures for principals of computer-using as well as non-using schools and for teachers of computer education courses and teachers of existing subjects. The latter group consisted of computer-using as well as non-computer using teachers from mathematics, science and mother tongue. This article raises the question to what extent attitudes play a role in the process of integrating computers in the existing curriculum. The article mainly focuses on lower secondary schools from 14 countries and shows that attitudes of prinicpals and teachers of existing subjects vary greatly, between as well as within countries. Moreover, it can be shown that attitudes covary in a meaningful way with the extent to which computers are used by computer-using teachers.

\section{References}

Becker, H.J. (1992). How our best computer using teachers differ from other teachers Paper presented at the AERA conference, San Francisco, April 1992 
Cox, M., Rhodes, V. \& Hall, J. (1988) The use of computer assisted leaming in pnmary schools: Some factors affecting the uptake. Computer Education, 12 (1), 173-178.

Fullan, M G., Miles, M.B. \& Anderson, S.E. (1988). Strategies for umplementing microcomputers in schools. The Ontario case. Ontario. Ministry of Education, Queen's printer.

Pelgrum, W.J. \& Plomp, Ty. (1991). The use of computers in education worldwide Results from the IEA 'Computers in Education' survey in 19 educational systems. Oxford: Pergamon.

Pelgrum, W.J. \& Schipper, A.T. (1992). Indicators of technology integration Paper presented at the European Conference on Educational Research. Enschede, June 1992.

The Author

WILLEM J. PELGRUM is a Research Officer at the Faculty of Educational Science and Technology, University of Twente, the Netherlands. He engaged in research in vocational education (1978-1980) and has functioned as National Research Coordinator of the IEA Second International Mathematics Study (1981-1983) and Second International Science Study (1983-1986). He presently is International Coordinator of the Computers in Education Study. His research interests are assessment and computers in the curriculum. 